\title{
Knowledge, attitude and practice of elders about sexuality
}

\author{
Raefa Refaat Alam * Doaa El Sayed Fadila \\ Gerontological Nursing Department, Faculty of Nursing, Mansoura University, Mansoura, Egypt
}

Received: May 3, 2016

DOI: $10.5430 /$ jnep.v6n12p24
Accepted: June 29, 2016

Online Published: July 18, 2016

\begin{abstract}
Background: Sexuality has been considered as one of the most natural and main aspects of life that affect an individual's identity as a human being. Not only the sexual activity provides happiness for older adults, it may also maintain a sense of self-esteem. Until recently, little attention was paid to sexuality of elderly people in many countries. Aim of the study was to identify knowledge, attitude and practice of elders about sexuality.

Methods: Descriptive design: This study was administered in three elderly clubs in Mansoura city, Dakahlia Governorate. Subjects: 158 elderly people attending those clubs were included in the study. Data were collected through using four tools; Socio-demographic data and factor affecting sexual relationship, Knowledge about sexuality, Attitude and practice of elderly about sexuality.

Results: The majority of the target subjects were females; more than half had moderate knowledge about sexuality and very few sexual relationships, most of the subjects reported that sexuality is unnecessary for them and that the most common risk factor influencing sexuality is the psychological condition.

Conclusions: It was concluded that a negative correlation occurred between knowledge and attitude and the majority of target subjects had a neutral attitude. Therefore, it is recommended to implement a health education program about sexuality. This will help to improve knowledge, attitude and practice concerning sexuality.
\end{abstract}

Key Words: Sexuality, Elderly, Attitude, Knowledge and practice

\section{NTRODUCTION}

Sexuality has been described as one of the most natural and basic aspects of life that affect an individual's identity as human being. Sexuality is a part of a larger concept known as intimacy. ${ }^{[1,2]}$ Although sexuality is considered a difficult issue to discuss for many clinicians, while intimacy is a subject that most people can discuss fairly comfortably, even as it relates to the elderly. Despite the physical ability to maintain a sexually active state in old age, various elements affect the elderly person's ability to remain sexually active. To ensure wellness and normality, sensitive attention to the maintenance and promotion of sexual function and identity is important. ${ }^{[3]}$

Human sexuality includes many kinds of intimate activity; as well as the sexual knowledge, beliefs, attitudes, and values of individuals. Sexual activity not only provides pleasure for older adults, it may also help adopt a sense of usefulness and self-esteem. These aspects of life often diminish following retirement. ${ }^{[4]}$ Sexual activity is a means for each partner to express love, affection, and loyalty. It can also enhance personal growth, creativity and communication. ${ }^{[5]}$

Previous studies conducted in USA by gerontological research have shown that knowledge and attitudes toward sex-

\footnotetext{
*Correspondence: Raefa Refaat Alam; Email: dr.raefa2015@gmail.com; Address: Gerontological Nursing Department, Faculty of Nursing, Mansoura University, Mansoura, Egypt.
} 
uality influence perceptions about sexual needs and feelings in later life. ${ }^{[6,7]}$ Besides, Hillman and Stricker (1994) ${ }^{[8]}$ revealed that there is generally a positive relationship between knowledge and attitudes toward sexuality in later life.

Until recently, sexuality of elderly people was not paid adequate attention in many countries, including Egypt. Although up to $8 \%$ of the total population will be elders by 2030 (WHO, 2011), yet most people consider even the idea of sexuality of elderly people as absurd. The thoughts of Egyptians were not different or negative about sexuality in elderly women than in elderly men. Because they believe in the virtue of monogamy, elderly women tend not to remarry when they lose their partners.

Over the last century, the life expectancy of the elderly people has increased all over the world. In the United States, the largest growing population is persons over the age of $65 .{ }^{[9]}$ Thus; it may be useful to talk about the personal aspects, "sex lives" of the elderly. When people in Egypt think of the elderly, they almost never think of this population having sex or good sex.

Normal aging results in physical changes in both men and women. These changes sometimes influence the ability to have and enjoy sex. As a woman ages, her vagina shortens and narrows. Her vaginal walls become thinner and also a little stiffer. Most women will have less vaginal lubrication. These changes could affect sexual function and/or pleasure. As men get older, impotence (also called erectile dysfunction) becomes more common. Erectile dysfunction is the loss of ability to have and keep an erection for sexual intercourse. ${ }^{[10]}$ Furthermore, some illnesses, disabilities, medicines, and surgeries can affect the ability to have and enjoy sex, such as: heart disease, stroke, arthritis, chronic pain, dementia, incontinence.

Although human beings are sexual from the moment of conception until death, yet there is a general societal thought that old people are or should be asexual and a false assumption exists that physical attractiveness is based on youth and beauty. The general public often considers sexuality among the elderly as non-existent, funny, and/or disgusting. In reality, many older people engage and enjoy sexual activities until their 80 s and even their 90 s. $^{[11]}$

There are various factors that can negatively affect sexual activity, including partner availability, health issues, alterations in sex drive, and medication use. ${ }^{[12]}$ Acute conditions, chronic or disabling conditions, and aging may require adaptations in the way we express our sexuality, but we do not cease to be sexual beings as we age. ${ }^{[13]}$ It is helpful to note that age itself abolishes neither the need nor the ability of

Published by Sciedu Press sexual activity. ${ }^{[14,15]}$

Hillman $(2008,2012)^{[16,17]}$ identified many elements in an older woman's life that influence her attitude towards sexuality. First of all, the unavailability of men often hinders an older woman's expression of her sexuality. Further, female sexuality as portrayed in the media is youth-based, which can negatively affect an older woman's overall attitude. Finally, societal attitudes supporting the idea that sexuality is the prerogative of young attractive women have been instrumental in depriving older women of their right to express their sexuality and achieve sexual satisfaction.

Therefore, the role of the gerontological nurse in the intervention of sexual dysfunction is to provide reassurance, education, and brief counseling. Raising the awareness of elderly people about both normal physiological and pathologic changes in sexual function in late life can decrease excessive fear and increase acceptance of these changes. For example, a man who does not understand the normal changes in erectile function may misinterpret them and think he is suffering from a sexual problem. Similarly, a woman may misinterpret the experience of vaginal dryness to mean that she does not want to have sex. It is recommended to implement a health education program about sexuality. This will help to improve knowledge, attitude and practice about sexuality. ${ }^{[2,15]}$

However, due to the tendency of Egyptian society to neglect the existence of sexuality in old age, older women, in particular, have been demotivated about addressing their sexuality needs or discussing them with health care professionals. Therefore, a better understanding of the sexuality of elderly people is a necessity for Egyptian people. Yet, only limited studies have been conducted on sexuality of elders in Egypt. Therefore, this study aimed to identify knowledge, attitudes and practice of elders about sexuality.

\section{Research questions}

(1) What is knowledge of elderly about sexuality?

(2) What are the attitudes and practice of elderly about sexuality?

(3) What are the relation between knowledge, attitudes and socio-demographic characteristics of elderly about sexuality?

\section{MeTHODS}

\subsection{Study design}

Cross-sectional descriptive design was used in this study.

\subsection{Settings}

This study was conducted in three elderly clubs available in Mansoura and talkha city, Dakahlia Governorate, Egypt. 


\subsection{Subjects}

The study subjects included 158 elderly of 258 of participant members in clubs agree to participate in the study, aged 60 years and above, currently married and educated (Primary and Secondary school, Diploma, baccalaureate and more), able to communicate and accept to participate in the study. Excluded elderly diagnosed with any psychiatric disorders.

\subsection{Tools of data collection}

In order to collect the necessary information for the study four tools were used.

Tool I: Socio demographic data and factors affecting sexual relationship structured interview schedule

It was developed by the researchers after reviewing literature and included two parts:

Part I: Socio-demographic data. It included:

- Socio-demographic data of the study sample namely; age, sex, marital status, level of education, occupation before retirement, current occupation, income, and living arrangement.

Part II: Factors affecting sexual relationship:

(1) Social factors such as: Lack of privacy, problems between couple, sudden disease of partner and newly hospital admission.

(2) Psychological condition such as: Negative view of body image, fear from death during sexual relation, anxiety, sadness and stress.

(3) Aging factors such as: Loss of health (medical disease), Lack of sexual desire, physiological changes and retirement or loss of job.

(4) Surgical factors such as: Hysterectomy, mastectomy, ovariectomy for women and prostectomy for males.

\section{Tool II: Knowledge about sexuality}

This tool was developed by the researchers, based on review of relevant literature. ${ }^{[18-20]}$ It consists of 32 statements to assess the level of knowledge about sexuality of elderly people. Statements were phrased either correctly or incorrectly and respondents had to choose "true", "false" or "don't know". Each correct answer was given a score of 2, and the wrong answer 1 and don't know 0 . Total score of knowledge ranged between 0-64. Knowledge scoring a total of less than 50\% was taken as having poor knowledge; those scoring $50 \%$ to less than $75 \%$ had moderate knowledge and those scoring $75 \%$ and above had good knowledge about sexuality.

\section{Tool III: Attitude of elderly about sexuality}

This tool was developed by the researchers, based on review of relevant literature. ${ }^{[8,21-23]}$ It consists of 19 statements to identify the attitude of elderly about sexuality, the score ranges from 1 to 5 where one given of the elders agrees with the statement and 5 if he absolutely disagrees. Negative statements were reversed for the purpose of analysis. Recode negative phrased items: \# 4, 6, 11, 12, and 15 (i.e., if the score is 5 in one of these items, the adjusted score is 1 ; if 4 , the adjusted score is 2 and so on...). All answers were summed up to obtain mean score, divided all participants into three groups (positive attitude, neutral attitude and negative attitude). Attitude of elderly about sexuality scoring of 32 and less (less than 33.3\%) were taken as having poor negative attitude, those scoring of 33 to 64 (33.3\% to 66.5\%) had neutral attitude and those scoring of 65 and above (66.6\% and above) had positive attitude of elderly about sexuality. Total scores ranged from 19 to 95 . A higher score indicates a more positive attitude.

\section{Tool IV: Practice of elderly about sexuality}

This tool was developed by the researchers, based on review of relevant literature. ${ }^{[5,24-26]}$ It consists of 7 questions regarding sexual practice of elderly people. Each question is answered by either yes or no. Yes is scored (1) and no is scored (2).

\subsection{Procedure}

Tools (I, II, III and IV) were developed by the researchers after a thorough review of literature. It was tested for its content validity by a jury of 9 experts in the related fields of Gerontological Nursing, Medical Surgical Nursing, Internal and Geriatric Medicine, and Community Health Nursing. The necessary modifications were done accordingly. The Tools (Knowledge about sexuality, Attitude of elderly about sexuality and practice of elderly about sexuality) were tested for its reliability on 10 elderly people. A test-retest measurement was done. These were selected from elderly club and the tools were repeated again for these elderly after two weeks. The reliability was assured by Spearman's correlation coefficient $r=0.886,0.899$ and 0.93 respectively. A pilot study was conducted on 15 elderly people in order to evaluate the clarity, applicability of the tool and to make the necessary modifications. These elders were not being included in the study sample.

An official letter was issued from the Faculty of Nursing, Mansoura University and forwarded to the manager of each club and Dean of each faculty separately in order to obtain their approval to carry out the study. After establishing a trustful relationship, each subject was interviewed by the researchers to explain the study purpose then study tools were completed by elders. The data was collected for a period of six months from the first of January 2015 till the end of June 2015. 


\subsection{Ethical considerations}

A verbal consent from the retirees to participate in the study was obtained after explanation of the study purpose. Privacy, confidentiality, anonymity and the right to withdraw at any time was assured.

\subsection{Statistical analysis}

The Statistical Package for Social Sciences "SPSS" software version 20.0 was utilized. The 0.05 level was used as the cut off value for statistical significance. Descriptive statistics: Count and percentage were used for describing and summarizing qualitative data. Arithmetic mean (X), Standard deviation (SD) were used as measures of central tendency and dispersion respectively for normally distributed quantitative data. Analytical statistics include: Independent sample $t$-test and F-test (One Way ANOVA).

\section{Results}

Table 1 shows the distribution of elders according to their socio-demographic characteristics. The age of the studied subjects ranged from 60 up to 74 years, with a mean age of $65.06 \pm 3.37$ years. Almost half of the elders (49.4\%) were 60 to less than 65 years, $39.2 \%$ were 65 to less than 70 years, and $11.4 \%$ were 70 years and more. Females were more prevalent in the study sample. They constituted $73.4 \%$ of the elders, while only $26.6 \%$ were males. More than half $(51.9 \%)$ of studied sample had secondary or diploma education, $33.5 \%$ were university graduate, while the rest of the sample $22.2 \%$ had only primary school education. Regarding the occupation the table shows that $69.6 \%$ of studied subjects had employed, while $30.4 \%$ had unemployed. Concerning elder's housing condition; it was observed that the majority studied subjects $(80.0 \%)$ was living in separate houses, while $19.0 \%$ were living in shared houses. More than half $(72.8 \%)$ of the studied subjects live in urban area and $27.2 \%$ living in rural area.

Table 2 shows the factors affecting sexuality among elderly people, the most common psychological factors were fear from death during sexual relation, anxiety and stress $61.4 \%$, $44.3 \%$ and $39.2 \%$ respectively. However, Social or surgical factors were reported by the same percent $(73.4 \%)$ of each while aging factors were reported by $68.4 \%$ of the elders. Among the main social factors reported by elders were lack of privacy and problems between partners 43.8 and $39.3 \%$ respectively.

Concerning the importance of sexuality for elderly, more than half of studied subjects $63.9 \%$ reported that sexuality was not important, while $36.6 \%$ reported it to be important. Regarding surgical condition reported by elders as being a factor the table show that hysterectomy was reported by

Published by Sciedu Press
$18.9 \%$ of the females, mastectomy by $16.4 \%$, and Ovarectomy by $5.2 \%$. While for males prostatectomy was reported by $19.04 \%$.

Table 1. Socio-Demographic Characteristics of studied subjects

\begin{tabular}{lll}
\hline Items & $\mathbf{N}=\mathbf{1 5 8}$ & $\mathbf{\%}$ \\
\hline Age (in years) & 78 & 49.4 \\
$60-$ & 62 & 39.2 \\
$65-$ & 18 & 11.4 \\
$70+$ & $65.06 \pm 3.37$ & \\
$\quad$ Mean \pm SD & & \\
Sex & 116 & 73.4 \\
$\quad$ Female & 42 & 26.6 \\
$\quad$ Male & & \\
Level of education & 23 & 22.2 \\
$\quad$ Primary & 82 & 51.9 \\
$\quad$ Secondary and diploma & 53 & 33.5 \\
$\quad$ University and more & & \\
Current occupation & 110 & 69.6 \\
$\quad$ Employed & 48 & 30.4 \\
$\quad$ Unemployed & & \\
Income & 90 & 57.0 \\
$\quad$ Enough & 68 & 43.0 \\
$\quad$ Not enough & & \\
Housing condition & 91 & 19.0 \\
$\quad$ Separate house & 67 & 72.8 \\
$\quad$ Shared house & & 27.2 \\
Residence & 115 & \\
$\quad$ Urban & 43 & \\
$\quad$ Rural & & \\
\hline & &
\end{tabular}

Table 2. Factors Affecting Sexuality among studied subjects

\begin{tabular}{|c|c|c|}
\hline Items & $\mathrm{N}=158$ & $\%$ \\
\hline Social factors & 116 & 73.4 \\
\hline Lack privacy & 69 & 43.8 \\
\hline Problems between couple & 62 & 39.3 \\
\hline Newly hospital admission & 24 & 15.2 \\
\hline Sudden disease & 21 & 13.3 \\
\hline Psychological factors & 140 & 88.6 \\
\hline Fear from death during sexual relation & 97 & 61.4 \\
\hline Anxiety & 76 & 44.3 \\
\hline Stress & 62 & 39.2 \\
\hline Sadness & 63 & 39.9 \\
\hline Negative view of body image & 18 & 11.4 \\
\hline Aging factors & 108 & 68.4 \\
\hline Loss of health & 143 & 90.5 \\
\hline Physiological changes & 107 & 67.7 \\
\hline Lack of sexual desire & 63 & 39.9 \\
\hline Retirement or loss of job & 52 & 32.9 \\
\hline \multicolumn{3}{|l|}{ Surgical factors } \\
\hline Female & 116 & 73.4 \\
\hline Hysterectomy & 22 & 18.9 \\
\hline Mastectomy & 19 & 16,4 \\
\hline Ovariectomy & 6 & 5.2 \\
\hline Male & 42 & 26.6 \\
\hline Prostectomy & 8 & 19.04 \\
\hline \multicolumn{3}{|l|}{ Importance of sexuality for elderly } \\
\hline Important & 57 & 36.1 \\
\hline Not important & 101 & 63.9 \\
\hline
\end{tabular}


Table 3 shows the Elder's responses for the knowledge questionnaire. The majority of elders $(85.4 \%)$ chose the correct answer "true", for "The older female has reduced vaginal lubrication secretion relative to younger female. Sexual relationship useful psychologically for the elderly and is the sexual relationship is affected as a result of physiological changes with age". $75.3 \%$ and $76.6 \%$ respectively selected the correct answer "true". The relatively most sexually active younger people tend to become the relatively most sexually active older People. 63.9\% chose the correct answer "true".

More than half of the elders $(58.9 \%, 58.2 \%$, and 54.4\%) chose the correct answer "true", for "If there is no obstacles or physical disorders can maintain sexual relations so well to reach the age of 80 and 90 years, the older female may experience painful intercourse due to reduced elasticity of the vagina and reduced and Erectile dysfunction elderly are likely to treat and cure it dynamically in many cases respectively". On the other hand, nearly half of the studied sample $(48.1 \%, 44.9 \%)$ chose the incorrect answer "true", for older females are sexually unresponsive and sexual activity in aged persons is often dangerous to their health.

Table 4 shows the practice of elderly people about sexual relation. More the half of elderly $(64.5 \%)$ reported a decrease in the number of sexual relationship while $65.2 \%$ reported no change in the duration during the sexual relationship. Husband consumption of steroids before the sexual relationship and the use of refreshments by the wife were given by $55.7 \%$ and $51.9 \%$ respectively. Regarding, use of different position according to the partner's health status and Continuation of sexual relationship were reported by $30.0 \%$ and $23.0 \%$ respectively.

Table 5 shows the relation between socio-demographic characteristics of elderly people about sexuality and their mean score of knowledge a significant relation between knowledge and level of education $(p=.000)$, income $(p=.001)$, housing condition $(p=.000)$, and residence $(p=.000)$. Table 6 shows the relation between socio-demographic characteristics of elderly people about sexuality their mean score of attitude a significant relation between attitude and income, and residence $(p=.000)$ of each.

Table 7 shows the correlation between knowledge and attitude of elderly people about sexuality. A negative correlation between knowledge and attitude ( $p=.345$ and $r=-.076)$ was found.

Figure 1 shows the total scores of knowledge about sexuality, more than half of the studied sample $52.2 \%$ had moderate knowledge score about sexuality, followed by $36.1 \%$ had a good knowledge score, while only $10.8 \%$ had poor knowl- edge.

Figure 2 illustrates the attitude of elderly people about sexuality. It clarifies that the majority of studied subjects $(95.6 \%)$ had a neutral attitude, only $4.4 \%$ had a positive attitude.

\section{Discussion}

Elderly people need love; sexual intimacy and in order maintain a healthy, enjoyable, and satisfying sexual life. ${ }^{[20,27]}$ In fact, a majority of older persons report moderate to high levels of sexual interest well into their $60 \mathrm{~s}, 70$ s and 80 s. $^{[28-30]}$ In critically reviewing the literature regarding the link between knowledge and attitudes about elderly sexuality questioned the extent to which one's knowledge influences one's attitudes about later life sexuality. Moreover, little studies have addressed the knowledge and attitudes about elderly sexuality of both health-care providers and the elderly themselves especially in Egypt. Therefore, this study was conducted to identify knowledge, attitude and practice of elders about sexuality.

The present study revealed that the mean age of $65.06 \pm 3.37$ years and females more than males (see Table 1). This higher mean age $71.8(\mathrm{SD}=10.66)$ was reported in a study conducted by Walker et al. $(1998,1999)^{[31,32]}$ in USA and that most of the respondents were women and married. The same finding was reported in other epidemiological studies. ${ }^{[20,33]}$

\subsection{Factors affecting sexuality among elderly people}

The present study revealed that lack of privacy, ill health, and fear from death and lack of sexual desire are the major factors affecting sexuality among elderly people (see Table 2 ). These factors were also reported from other epidemiological studies (Kaplan, 1990; Trudel et al. 2010), ${ }^{[34,35]}$ age is not the only cause of sexual dysfunction (Sharpe, 2004). ${ }^{[36]}$ In the same line study done by Deacon et al. (1995) $)^{[15]}$ in USA stated the lack of privacy is a major obstacle to sexual expression. These results contradict with a study conducted by Kalra et al. (2011) ${ }^{[26]}$ in India found that the majority of study subjects did not have any diagnosed major illness.

Regarding the importance of sexuality in old age, the present study revealed that more than half of studied sample reported sexuality to be not important for them (see Table 2). This may be explained by the differences in cultural behaviors and attitude of elderly toward sexuality. This result is agreement with Gottand and Hinchliff (2003) ${ }^{[29]}$ who found that if the older people are not sexually active, sex is not important to them. This result contradicts the study done by Walker et al. $(1998)^{[31]}$ in USA who revealed that of those 60-to-80-yearold men and women stated that sexuality was important to them. 
Table 3. Knowledge of elderly people about sexuality

\begin{tabular}{|c|c|c|c|c|c|c|c|}
\hline \multirow{2}{*}{ Items } & \multicolumn{2}{|c|}{ True } & \multicolumn{2}{|c|}{ False } & \multicolumn{2}{|c|}{ Unknown } & \multirow{2}{*}{$\begin{array}{l}\text { Correct } \\
\text { response }\end{array}$} \\
\hline & $\mathbf{N}$ & $\%$ & $\mathbf{N}$ & $\%$ & $\mathbf{N}$ & $\%$ & \\
\hline Sexual activity in aged persons is often dangerous to their health. & 71 & 44.9 & 52 & 32.9 & 35 & 22.2 & False \\
\hline $\begin{array}{l}\text { Elderly over the age of } 60 \text { typically take longer to attain an erection of } \\
\text { their penis than do younger males. }\end{array}$ & 69 & 43.7 & 44 & 27.8 & 45 & 28.5 & True \\
\hline $\begin{array}{l}\text { Males over the age of } 60 \text { usually experience a reduction in intensity of } \\
\text { orgasm relative to younger males. }\end{array}$ & 90 & 57.0 & 39 & 24.7 & 29 & 18.4 & True \\
\hline $\begin{array}{l}\text { The firmness of erection in aged males if often less than that of } \\
\text { younger persons. }\end{array}$ & 77 & 48.7 & 42 & 26.6 & 39 & 24.7 & True \\
\hline $\begin{array}{l}\text { The older female has reduced vaginal lubrication secretion relative to } \\
\text { younger females. }\end{array}$ & 135 & 85.4 & 14 & 8.9 & 9 & 5.7 & True \\
\hline $\begin{array}{l}\text { The aged female takes longer to achieve adequate vaginal lubrication } \\
\text { relative to younger females. }\end{array}$ & 101 & 63.9 & 24 & 15.2 & 33 & 20.9 & True \\
\hline $\begin{array}{l}\text { The older female may experience painful intercourse due to reduced } \\
\text { elasticity of the vagina and reduced. }\end{array}$ & 92 & 58.2 & 30 & 19.0 & 36 & 22.8 & True \\
\hline Sexuality is typically a lifelong need. & 67 & 42.4 & 91 & 57.6 & 0 & 0.0 & True \\
\hline Sexual behavior in older people increases the risk of heart attack. & 75 & 47.5 & 63 & 39.9 & 20 & 12.7 & False \\
\hline Most males over the age of 60 unable to engage in sexual intercourse. & 53 & 33.5 & 71 & 44.9 & 34 & 21.5 & False \\
\hline $\begin{array}{l}\text { The relatively most sexually active younger people tend to become the } \\
\text { relatively most sexually active older People. }\end{array}$ & 101 & 63.9 & 24 & 15.2 & 33 & 20.9 & True \\
\hline $\begin{array}{l}\text { There is evidence that the sexual relationship with older physically } \\
\text { benefits. }\end{array}$ & 135 & 85.4 & 14 & 8.9 & 9 & 5.7 & True \\
\hline Sexual relationship useful psychologically for the elderly. & 121 & 76.6 & 0 & 0.0 & 37 & 23.4 & True \\
\hline Older women do not respond to the sexual relationship. & 34 & 21.5 & 124 & 78.5 & 0 & 0.0 & False \\
\hline Older females are sexually unresponsive. & 76 & 48.1 & 59 & 37.3 & 23 & 14.6 & False \\
\hline Prescribed medications affect sexual relationship. & 76 & 48.1 & 59 & 37.3 & 23 & 14.6 & False \\
\hline $\begin{array}{l}\text { Elderly women have a physiological changes affect a sexual } \\
\text { relationship. }\end{array}$ & 53 & 33.5 & 71 & 44.9 & 34 & 21.5 & False \\
\hline $\begin{array}{l}\text { Basically, changes with advanced age }(60+) \text { in sexuality involve a } \\
\text { slowing of response time rather than a reduction of interest in sex. }\end{array}$ & 135 & 85.4 & 14 & 8.9 & 9 & 5.7 & True \\
\hline $\begin{array}{l}\text { Is the sexual relationship is affected as a result of taking certain } \\
\text { medications for a long time, such as tranquilizers and diuretics etc. }\end{array}$ & 82 & 51.9 & 55 & 34.8 & 21 & 13.3 & True \\
\hline $\begin{array}{l}\text { There is a decrease in frequency of sexual activity with older age in } \\
\text { males. }\end{array}$ & 84 & 53.2 & 67 & 42.4 & 7 & 4.4 & True \\
\hline $\begin{array}{l}\text { There is a greater decrease in male sexuality with age than there is in } \\
\text { female sexuality. }\end{array}$ & 54 & 34.2 & 38 & 24.1 & 66 & 41.8 & True \\
\hline Heavy consumption of cigarettes may diminish sexual desire. & 56 & 35.4 & 56 & 35.4 & 46 & 29.1 & True \\
\hline $\begin{array}{l}\text { An important factor in the maintenance of sexual responsiveness in } \\
\text { the aging male is the consistency of sexual activity throughout his life. }\end{array}$ & 101 & 63.9 & 24 & 15.2 & 33 & 20.9 & True \\
\hline $\begin{array}{l}\text { The ending of sexual activity in old age is most likely and primarily } \\
\text { due to social and psychological causes rather than biological and } \\
\text { physical causes. }\end{array}$ & 93 & 58.9 & 39 & 24.7 & 26 & 16.5 & True \\
\hline Exercise of the factors that negatively affected the sexual relationship. & 45 & 28.5 & 74 & 46.8 & 39 & 24.7 & False \\
\hline $\begin{array}{l}\text { There is no desire in the sexual relationship in women after } \\
\text { menopause. }\end{array}$ & 25 & 15.8 & 86 & 54.4 & 47 & 29.7 & False \\
\hline $\begin{array}{l}\text { Sexual impotence in men growing with age compared to younger } \\
\text { siblings. }\end{array}$ & 73 & 46.2 & 59 & 37.3 & 26 & 16.5 & True \\
\hline $\begin{array}{l}\text { Erectile dysfunction elderly are likely to treat and cure it dynamically } \\
\text { in many cases. }\end{array}$ & 86 & 54.4 & 54 & 34.2 & 18 & 11.4 & True \\
\hline $\begin{array}{l}\text { If there is no obstacles or physical disorders can maintain sexual } \\
\text { relations so well to reach the age of } 80 \text { and } 90 \text { years. }\end{array}$ & 93 & 58.9 & 48 & 30.4 & 17 & 10.8 & True \\
\hline $\begin{array}{l}\text { Is the sexual relationship is affected as a result of physiological } \\
\text { changes with age. }\end{array}$ & 119 & 75.3 & 22 & 13.9 & 17 & 10.8 & True \\
\hline $\begin{array}{l}\text { The sexual relationship as a result of the presence of chronic disease } \\
\text { such as diabetes/pressure/diseases is affected by heart disease, etc. }\end{array}$ & 79 & 50.0 & 62 & 39.2 & 17 & 10.8 & False \\
\hline $\begin{array}{l}\text { The nature of the foods covered by the elderly have an impact on the } \\
\text { sexual relationship. }\end{array}$ & 75 & 47.5 & 48 & 30.4 & 35 & 22.2 & True \\
\hline
\end{tabular}

Published by Sciedu Press 
Table 4. Practice of Elderly People about Sexual relation

\begin{tabular}{|c|c|c|}
\hline Items & $\mathbf{N}=158$ & $\%$ \\
\hline \multicolumn{3}{|c|}{ Decrease in the number of usual sexual relationship. } \\
\hline Yes & 102 & 64.5 \\
\hline No & 56 & 53.4 \\
\hline \multicolumn{3}{|c|}{ Change in duration of sexual relationship. } \\
\hline Yes & 55 & 34.8 \\
\hline No & 103 & 65.2 \\
\hline \multicolumn{3}{|c|}{ Longer periods of foreplay before sexual intercourse. } \\
\hline Yes & 40 & 25.3 \\
\hline No & 118 & 74.7 \\
\hline \multicolumn{3}{|c|}{ Wife using of refreshments before the sexual relationship. } \\
\hline Yes & 82 & 51.9 \\
\hline No & 76 & 48.1 \\
\hline \multicolumn{3}{|c|}{ Husband consumption steroids before the sexual relation. } \\
\hline Yes & 88 & 55.7 \\
\hline No & 70 & 44.3 \\
\hline \multicolumn{3}{|c|}{$\begin{array}{l}\text { Use different position according to the partners health } \\
\text { status. }\end{array}$} \\
\hline Yes & 48 & 30.4 \\
\hline No & 110 & 69.6 \\
\hline \multicolumn{3}{|c|}{ Now continuation of sexual relationship. } \\
\hline Yes & 37 & 23.4 \\
\hline No & 121 & 76.6 \\
\hline Mean \pm SD & $12.07 \pm 2.2$ & \\
\hline
\end{tabular}

Table 5. Relation between socio-demographic characteristics of elderly people about sexuality and their mean score of knowledge

\begin{tabular}{|c|c|c|c|}
\hline Variables & $\mathbf{N}=158$ & Mean \pm SD & $P$ \\
\hline \multicolumn{3}{|l|}{ Age (in years) } & \multirow{4}{*}{.040} \\
\hline $60-$ & 78 & $18.50 \pm 6.05$ & \\
\hline $65-$ & 62 & $15.79 \pm 7.39$ & \\
\hline$\geq 70$ & 18 & $18.78 \pm 6.15$ & \\
\hline \multicolumn{3}{|l|}{ Sex } & \multirow{3}{*}{.805} \\
\hline Female & 116 & $17.71 \pm 7.90$ & \\
\hline Male & 42 & $17.38 \pm 6.27$ & \\
\hline \multicolumn{3}{|l|}{ Level of education: } & \multirow{4}{*}{$.000^{*}$} \\
\hline Primary & 23 & $14.13 \pm 5.08$ & \\
\hline Secondary and diploma & 82 & $16.11 \pm 6.61$ & \\
\hline University+ & 53 & $21.17 \pm 5.92$ & \\
\hline \multicolumn{3}{|l|}{ History of work } & \multirow{3}{*}{$.110^{*}$} \\
\hline Employed & 110 & $17.98 \pm 7.13$ & \\
\hline Unemployed & 48 & $16.29 \pm 5.54$ & \\
\hline \multicolumn{3}{|l|}{ Income } & \multirow{3}{*}{$.001^{*}$} \\
\hline Enough & 90 & $19.04 \pm 6.56$ & \\
\hline Not enough & 68 & $15.38 \pm 6.39$ & \\
\hline \multicolumn{3}{|l|}{ Housing condition } & \multirow{3}{*}{$.000^{*}$} \\
\hline Separate home & 91 & $20.24 \pm 6.24$ & \\
\hline Shared home & 67 & $13.70 \pm 5.40$ & \\
\hline \multicolumn{3}{|l|}{ Residence } & \multirow{3}{*}{$.000^{*}$} \\
\hline Rural & 43 & $15.23 \pm 3.36$ & \\
\hline Urban & 115 & $18.30 \pm 7.44$ & \\
\hline
\end{tabular}

\subsection{Knowledge of elderly people about sexuality}

Concerning the knowledge of elderly people about sexuality, the current study showed that more than half of the studied sample had moderate knowledge about sexuality (see Figure 1). This may be because they were raised during a time when scientific sexual information was not readily available or widely openly discussed. In the same direction, Rendon (2003) in USA stated that respondents had a moderate level of Knowledge about sexuality. ${ }^{[7]}$ Another study done by (Bouman1 et al. 2006) who revealed that the elderly today have a relative lack of formal knowledge about sexual functioning and physiology. ${ }^{[37]}$ These findings are consistent with previous researches which have indicated that older adults possess moderate or little knowledge. Masters and Johnson (1966) found that older adults had received little or no information from outside sources. ${ }^{[38]}$ Similarly, study by Walker et al. (1999) in USA and Adams et al. (1990) found that participants of a 90-minute workshop on sexuality possessed moderate knowledge on sexuality before the workshop and on the whole, respondents were moderately knowledgeable. ${ }^{[32,39]}$ This result disagrees with other studies conducted by White \& Catania (1982) in Washington which stated that the elderly persons have significantly less knowledge about elderly sexuality than middle-aged children of Elderly parents and caretakers of older adults. ${ }^{[40]}$ Elderly participants in Adams et al. (1990) study also were found to possess little knowledge about elderly sexuality. ${ }^{[39]}$ White (1982 b) has suggested that elderly persons typically may have had little access to information regarding sexuality and aging. ${ }^{[1]}$ When controlling for the effect of an undergraduate sexuality course, samples of both older adults and college students were found to possess similarly low levels of knowledge Story, 1989 in USA. ${ }^{[42]}$

\subsection{Attitude of elderly people about sexuality}

Although general societal attitudes toward elderly sexuality have been described as highly negative. ${ }^{[13,31]}$ This result agrees with the current study which found that the majority of study subjects had a neutral attitude but the lowest percent had a positive attitude (see Figure 2). This may be related to the cultural and religious beliefs of eastern community who beliefs that life is without problems if there are no sexual relationship problems and elderly do not want to talk about the sexual relationship with specialists. This result is in harmony with the study of Story (1989) in USA who found that the general attitude of both residents and students towards the sexuality of older people were very neutral or moderate, but their attitude towards the sexual behaviors, such as masturbation and sex outside the marriage, were less positive. ${ }^{[42]}$ This was also consistent with previous studies that indicated that older adults showed interest in sex and felt sexual needs but believed their desires were shameful, sinful, and intolerable. ${ }^{[43,44]}$ Another study found that older adults who maintained sexual activity also had positive attitudes toward sexuality. ${ }^{[6,43]}$ Another study noted that older adults continue to have a desire for sexual relationships; however, societal attitudes, culture, and/or religious beliefs often 
impact those feelings negatively. ${ }^{[44,45]}$

Table 6. Relation between Socio-Demographic Characteristics of Elderly People about Sexuality and their mean score of attitude

\begin{tabular}{|c|c|c|c|}
\hline Variables & $N=158$ & Mean \pm SD & $P$ \\
\hline \multicolumn{4}{|l|}{ Age (in years) } \\
\hline $60-$ & 78 & $56.46 \pm 4.73$ & \multirow{3}{*}{.594} \\
\hline $65-$ & 62 & $57.21 \pm 4.27$ & \\
\hline$\geq 70$ & 18 & $56.44 \pm 4.38$ & \\
\hline \multicolumn{4}{|l|}{ Sex } \\
\hline Female & 116 & $57.88 \pm 4.77$ & \multirow[t]{2}{*}{.058} \\
\hline Male & 42 & $56.34 \pm 4.35$ & \\
\hline \multicolumn{4}{|l|}{ Level of education } \\
\hline Primary & 23 & $54.87 \pm 4.76$ & \multirow{3}{*}{.357} \\
\hline Secondary and diploma & 82 & $56.88 \pm 4.86$ & \\
\hline University+ & 53 & $57.17 \pm 3.85$ & \\
\hline \multicolumn{4}{|l|}{ History of work } \\
\hline Employed & 110 & $56.67 \pm 4.58$ & \multirow[t]{2}{*}{.735} \\
\hline Unemployed & 48 & $56.94 \pm 4.36$ & \\
\hline \multicolumn{4}{|l|}{ Income } \\
\hline Enough & 90 & $55.46 \pm 3.96$ & \multirow[t]{2}{*}{$.000^{*}$} \\
\hline Not enough & 68 & $58.47 \pm 4.63$ & \\
\hline \multicolumn{4}{|l|}{ Housing condition } \\
\hline Separate home & 91 & $56.96 \pm 4.34$ & \multirow[t]{2}{*}{.511} \\
\hline Shared home & 67 & $56.48 \pm 4.72$ & \\
\hline \multicolumn{4}{|l|}{ Residence } \\
\hline Rural & 43 & $54.51 \pm 4.24$ & \multirow[t]{2}{*}{$.000^{*}$} \\
\hline Urban & 115 & $57.59 \pm 4.32$ & \\
\hline
\end{tabular}

Table 7. Correlation between Knowledge and Attitude of studied subjects about Sexuality

\begin{tabular}{lll}
\hline Attitude & $\boldsymbol{r}$ & $\boldsymbol{P}$ \\
\hline Knowledge & -.076 & .345 \\
\hline
\end{tabular}

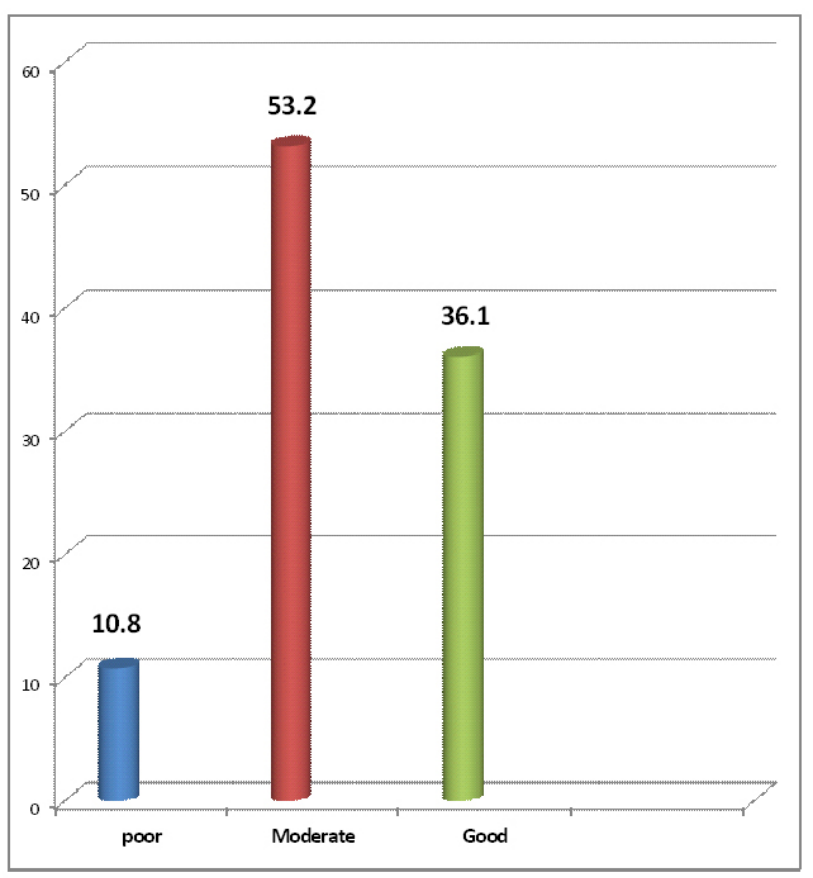

Figure 1. Total knowledge score of elderly people about sexuality

Published by Sciedu Press

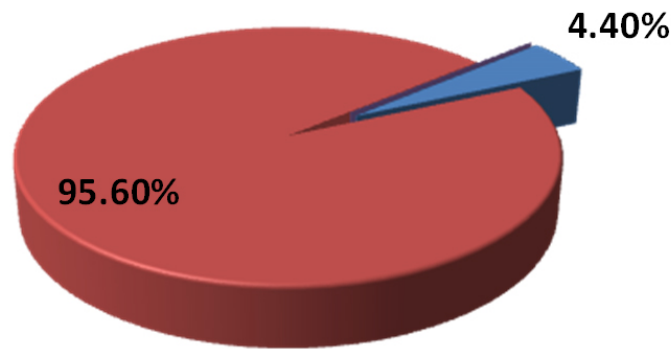

Positive neutral

Figure 2. Attitude of elderly people about sexuality

Regarding practice of sexuality, the present study found that more than half of elders decrease number of sexual relationship, change in the duration of the sexual act and discontinuation of sexual relationship (see Table 4). This may be related to physiological changes in the reproductive system in females and prostate function in males. There are numerous studies and arguments finding decreasing sexual interest and action in old age ${ }^{[46-51]}$ For example, data indicates that the prevalence of sexual activity declines with age in the United States. This transition has been explained by biological and psychological factors, diseases, mental condition, boredom in the relationship, and widowhood. ${ }^{[28,43]}$ This is in discrepancy with a study of kalra et al. (2011) in India who reported that a larger percentage of men $(83.4 \%)$ were maintaining their sexual activity even after the age of 50 years. ${ }^{[26]}$ All others had stopped their sexual activity at some time or the other. This was slightly more than that reported by Helgason et al. (1996) and Antonovsky et al. (1990) where in approximately $71 \%$ men in their sample were having sexual intercourse after the age of 60. ${ }^{[52,53]}$ Johnson (1996), added that elderly people were often sexually active and interested in continuing these activities. ${ }^{[54]}$ Hodson and Skeen (1994) stated that sexual interest and acceptance of sexual activity is present in 60-90-year-old individuals. ${ }^{[22]}$

The present study revealed that a statistically significant relation between knowledge, level of education, income, housing condition and residence (see Table 5). This attribute the level of awareness and more educated in general topic like sexuality. This result is in agreement with study by Rendon (2003) and walker et al. (1998) in USA who revealed that significant relationship was found between the scores of knowledge and the demographic characteristics (e.g., education, income, and marital status) of the respondents. ${ }^{[7,31]}$

Regarding a correlation between knowledge and attitude, the current study found a negative correlation between knowledge and attitude (see Table 7). This result is consistent with 
a study by Rendon (2003) in USA who found that greater knowledge was significantly associated with a more permissive attitude. ${ }^{[7]}$ Luketich $(1991)^{[55]}$ in USA examined the relationship between knowledge and attitudes toward elderly sexuality among a sample of 42 graduate nursing students. The correlation between the students' knowledge and attitudes scores on the ASKAS was not significant, $r=.13$. Additionally, Class et al. (1986) ${ }^{[56]}$ found empirical evidence that knowledge and attitudes toward elderly sexuality were significantly correlated, but negatively, $r=-.30$. This finding is not consistent with a study of Rowland and Haynes $(1978)^{[57]}$ who found more knowledge was significantly associated with attitudes. Another study by White and Catania $(1982)^{[40]}$ indicated a positive linear relationship between knowledge and attitudes in three different populations: elderly persons, middle-aged children of elderly persons, and nursing staff. However, in contrast with his previous findings, White reported that knowledge and attitudes were not significantly related.

\section{LIMITATIONS OF THE STUDY}

Some of elderly people attending the study settings refused to participate in the study because differences in cultural be- haviors. They constituted 63 elderly (45 male and 18 female). This influences the results to representation.

\section{RECOMMENDATIONS}

(1) Improving elder's knowledge and practice through education program, and counseling.

(2) Educate and increase awareness not only of older adults but the society as well so that older adults achieve their full potential as sexual beings.

(3) Further studies involving a large number of elders are needed to confirm these findings

\section{Conclusion}

It can be concluded that elderly people had a moderate level of knowledge about sexuality and the majority of studied subjects had a neutral attitude. Also, a negative correlation between knowledge and attitude and poor practice was found.

\section{CONFlicts of InTERest Disclosure}

The author declares that there is no conflict of interest statement.

\section{REFERENCES}

[1] Lueckenotte A. Gerontologic Nursing. London: Mosby Com. 2000; 217-31.

[2] Lueckenotte A. Gerontological Nursing. 2nd. London: Mosby Company. 2000; 120: 44.

[3] Watters Y, Boyd T. Sexuality in later life: opportunity for reflections for healthcare providers. Sexual and Relationship Therapy. 2009; 24(3-4): 307-315. http://dx.doi.org/10.1080/14681990903 398047

[4] Meiner S, Lueckenotte A. Gerontologic nursing. 3th ed. USA: Mosby Com. 2006.

[5] Nay R, Garratt S. Nursing Older People issues And Innovation, Philadephia: Mosby Company. 2004; 276: 90.

[6] Rendon R. Older adults' knowledge of and attitudes toward sexuality a thesis Presented to the Department of Social Work. California State University, Long Beach. 1997, California State University, Long Beach. May 2003. Master of Social Work.

[7] Steinke E. knowledge and attitudes of older adults about sexuality doctora of philosophy. Kansas State University. College of education. 1987.

[8] Hillman J, Stricker G. A linkage of knowledge and attitudes toward elderly sexuality: Not necessarily a uniform relationship. The Gerontologist. 1994; 24(2): 256-260. http://dx.doi.org/10.1093/g eront/34.2.256

[9] Jennifer A, Crittenden MSW, Lindsay Day LSW. Aging, relationships, \& sexuality: tools and resources for geriatric care managers. Journal of Geriatric Care Management. 2012.

[10] Anastasiadis AG, Davis AR, Ghafar MA, et al. The epidemiology and definition of female sexual disorders. World Journal of Urology. 2002; 20: 74-78. PMid:12107536 http://dx.doi .org/10.1007 /s00345-002-0272-5
[11] Chapman J. Knowledge and Attitudes of Sexuality in the Elderly Among Educators of Health Care Professionals.A thesis Submit!ed in Partial Fulfilment of the Requirements for the ward of Master of Psychology Faculty of Community Services, Education and Social Sciences. Edith Cowan University, Joondalup. 1999.

[12] Montgomery K. Sexual Desire Disorders Psychiatry (Edgmont). 2008 Jun; 5(6): 50-55.

[13] Kass MJ. Geriatric Sexuality Breakdown Syndrome. International Journal of Aging and Human Development. 1981; 13: 71-77. http://dx.doi.org/10.2190/4A16-06AH-HL5A-WKC3

[14] Kellert JM. Sexuality in Later Life. Reviews in Clinical Gerontology. 1993; 3: 309-314. http://dx.doi .org/10.1017/S0959259800 003531

[15] Deacon S, Minichiello V, Plummer D. Sexuality and older people: revisiting the assumptions. Educational Gerontology. 1995; 21(5): 497-513. http://dx.doi.org/10.1080/0360127950210509

[16] Hillman J. Sexual issues and aging within the context of work with older adult patients. Professional Psychology: Research and Practice. 2008; 39: 290-297. http://dx.doi.org/10.1037/0735-7028. 39.3 .290

[17] Hillman J. Attitudes toward Sexuality and Aging. Sexuality and Aging. 29 February 2012.

[18] White CB, Catania J. Sexual education for aged people, people who work with the aged and families of aged people. International Journal of Aging and Human Development. 1981; 15: 121-138. http://dx.doi.org/10.2190/NB3K-P604-U5XE-TEJ0

[19] Woods N. Human Sexuality, CV Mosby: St Louis. 1984.

[20] Willert A, Semans M. knowledge and attitudes about later life sexuality: what clinicians need to know about helping the elderly? Contemporary Family Therapy. 2000 Human Sciences Press, Inc. 2000. 
[21] Hendrick S, et al. Multidimensionality of Sexual Attitudes. Journal of Sex Research. 1987; 23: 502-526. http://dx.doi.org/10.10 80/00224498709551387

[22] Hodson D, Skeen P. Sexuality and aging: The hammerlock of myths. Journal of Applied Gerontology. 1994; 13(3): 219-235. http://dx.doi.org/10.1177/073346489401300301

[23] Ja Lee1K, et al. Study on Knowledge and Attitudes Regarding Sexuality of Elderly People in Korea. Journal of Korean Academy of Nursing. 2007; 37(2): 179-184.

[24] Ebersole P, Hess P, Luggen AS. Toward healthy aging: Human needs and nursing response. London: Mosby Com. 2004; 466-88.

[25] Papaharitou S, et al. Factors associated with sexuality in later life: an exploratory study in a group of Greek married older adult. Archives of Gerontology and Geriatrics. 2007. PMid:17532065

[26] Kalra G, Subramanyam A, Pinto C. Sexuality: Desire, activity and intimacy in the elderly. Indian J Psychiatry. 2011 Oct-Dec; 53(4): 300306. PMid:22303037 http://dx.doi .org/10.4103/0019-554 5.91902

[27] Yana E, Wub A, Hoa P, et al. Older Chinese men and women's experiences and understanding of sexuality. Culture, Health \& Sexuality. 2011; 13(9): 983-999. PMid:21824033 http://dx.doi.org/10. 1080/13691058.2011.605471

[28] DeLamater J. Sexual Desire in Later Life. Desire, activity and intimacy in the elderly. The Journal of Sex Research Sexuality. 2005; 42(2): 138-149. PMid: 16123844

[29] Gott M, Hinchliff S. How important is sex in later life? The views of older people. Social Science \& Medicine. 2003; 1617-162. http://dx.doi.org/10.1016/S0277-9536(02)00180-6

[30] Gott M, Hinchliff S. Sex and aging: A gendered issue? In Gender and aging: Changing roles and relationships, ed. S. Arber, K. Davidson, and J. Ginn. Buckingham, UK: Open University Press. 2003.

[31] Walker B, Osgood N, Richardson J, et al. staff and elderly knowledge and attitudes toward elderly sexuality. Educational Gerontology. 1998; 24(5): 471-489. http://dx.doi.org/10.1080/0360127 980240504

[32] Walker B, Ephross P. Knowledge and Attitudes Toward Sexuality of a Group of Elderly. Journal of Gerontological Social Work. 1999. http://dx.doi.org/10.1300/J083v31n01_06

[33] Gaa A, Shafighi S. Age, religious beliefs and sexual attitudes. Journal of Sex Research. 2002; 39(3): 207-216. PMid:12476268

[34] Kaplan HS. Sex, intimacy, and the aging process. J Am Acad Psychoanal. 1990; 12: 185-205.

[35] Trudel G, Turgeon L, Piché L. Sexual and marital aspects of old age. Sex Relationship Ther. 2010; 15: 381-406. http://dx.doi.org/1 $0.1080 / 713697433$

[36] Sharpe TH. Introduction to sexuality in later life. Family J. 2004; 12: 199-205. http://dx.doi.org/10.1177/0022167804264106

[37] Bouman W, Arcelus J, Benbow S. Nottingham Study of Sexuality \& Ageing (NoSSA I). Attitudes regarding sexuality and older people: a review of the literature. Sexual and Relationship Therapy. 2006. http://dx.doi.org/10.1080/14681990600618879

[38] Masters WH, Johnson VE. Human sexual response. Boston: Little Brown. 1966.

[39] Adams MA, Rojas-Camero C, Clayton K. A small-group sex education/intervention model for the well elderly: A challenge for educators. Educational Gerontology. 1990; 76: 601-608. http: //dx.doi.org/10.1080/0380127900160609

[40] White CB, Catania JA. Psych educational intervention for sexuality with the aged, family members of the aged, and people who work with the aged. International Journal of Aging and Human Development. 1982; 15: 121-138. PMid:7183559 http://dx.doi.org/1 $0.2190 /$ NB3K-P604-U5XE-TEJ0
[41] White CB. Sexual interest, attitudes, knowledge, and sexual history in relation to sexual behavior in the institutionalized aged. Archives of Sexual Behavior. 1982b; 11: 11-21. PMid:7073466 http://dx.doi.org/10.1007/BF01541362

[42] Story MD. Knowledge and attitudes about the sexuality of older adults among retirement home residents. Educational Gerontology. 1989; 15: 515-526. http://dx.doi.org/10.1080/038012789 0150507

[43] Tramer R, Schluderman E. Sexuality, locus of control beliefs and life satisfaction in community elderly males and females. Paper presented to the Canadian Psychological Association Annual Convention, Winnipeg. 1983.

[44] Starr B, Weiner MB. Sex and sexuality in the mature years. New York: Stein \& Day. 1981.

[45] Salon E. Administrators' knowledge and attitudes regarding sexuality among the elderly living in residential care facilities a thesis Master of Social Work. BA, 1996, University of California, Los Angeles. May 2000.

[46] Laumann EO, Nicolosi A, Glasser DB, et al. Sexual problems among women and men aged 40-80: Prevalence and Correlates. 2005.

[47] Dennerstein L, Lehert P. Women's sexual functioning, lifestyle, midage, and menopause in 12 European countries. Menopause. 2004; 11(6): 778-785. PMid:15543029 http://dx.doi.org/10.1097 101.GME.0000138544.50670.CC

[48] Beutel ME, Schumacher J, Weidner W, et al. Sexual activity, sexual and partnership satisfaction in ageing men-Results from a German representative community study. Andrologia. 2001; 34: 22-28. http://dx.doi.org/10.1046/j.0303-4569.2001.00473.x

[49] Araujo AB, Mohr BA, McKinlay JB. Changes in sexual function in middle-aged and older men: Longitudinal data from the Massachusetts male aging study. Journal of the American Geriatrics Society. 2004; 52: 1502-1509. PMid:15341552 http://dx.doi.o $\mathrm{rg} / 10.1111 / \mathrm{j} .0002-8614.2004 .52413 . \mathrm{x}$

[50] Blanker MH, Bosch JL, Groeneveld FPMJ, et al. Erectile and ejaculatory dysfunction in a community based sample of men 50 to 78 years old: Prevalence, concerns, and relation to sexual activity. Urology. 2001; 57: 763-768. http://dx.doi.org/10.1016/S0090-429 $5(00) 01091-8$

[51] Marsiglio W, Donnelly D. Sexual relations in later life: A national study of married persons. Journal of Gerontology. 1991; 46(6): 338344. http://dx.doi.org/10.1093/geronj/46.6.S338

[52] Helgason AR, Adolfsson J, Dickman P, et al. Sexual desire, erection, orgasm and ejaculatory functions and their importance to elderly Swedish men: A population-based study. Age Ageing. 1996; 25: 285-91. http://dx.doi.org/10.1093/ageing/25.4.285

[53] Antonovsky H, Sadowsky M, Maoz B. Sexual activity of aging men and women: An Israeli study. Behav Health Aging. 1990; 3: 151-61.

[54] Johnson B. Older adults and sexuality: A multidimensional perspective. Journal of Gerontological Nursing. 1996; 22(2): 6-15. http://dx.doi.org/10.3928/0098-9134-19960201-06

[55] Luketich GF. Sex and the elderly: What do nurses know? Educational Gerontology. 1991; 17: 573-580. http://dx.doi.org/10.1080 10360127910170604

[56] Class JC, Mustian RD, Carter LR. Knowledge and attitudes of health care providers toward sexuality in the institutionalized elderly. Educational Gerontology. 1986; 12: 465-475. http://dx.doi.org/1 $0.1080 / 0380127860120506$

[57] Rowland KF, Haynes SN. A sexual enhancement program for elderly couples. Journal of Sex and Marital Therapy. 1978; 4: 91113. PMid: 722820 http://dx.doi.org/10.1080/00926237808 403010 